\title{
Household migration in disaster impact analysis: incorporating behavioural responses to risk
}

\author{
Trond G. Husby ${ }^{1}$ Elco E. Koks ${ }^{2}$
}

Received: 30 June 2014/ Accepted: 19 January 2017/Published online: 2 February 2017

(C) The Author(s) 2017. This article is published with open access at Springerlink.com

\begin{abstract}
Detailed estimates of economy-wide disaster losses provide important inputs for disaster risk management. The most common models used to estimate losses are inputoutput (IO) and computable general equilibrium (CGE) models. A key strength of these models is their ability to capture the ripple effects, whereby the impacts of a disaster are transmitted to regions and sectors that are not directly affected by the event. One important transmission channel is household migration. Changes in the spatial distribution of people are likely to have substantial impacts on local labour and housing markets. In this paper, we argue that IO and CGE models suffer from limitations in representing household migration under disaster risk. We suggest combining IO and CGE models with agent-based models to improve the representation of migration in disaster impact analysis.
\end{abstract}

Keywords Input-output - Computable general equilibrium · Agent-based models · Households migration · Disaster risk

\section{Introduction}

On 31 March 2014, Working Group II of the Intergovernmental Panel of Climate Change (IPCC) published its contribution to the latest in a series of Assessment Reports on the impact of climate change (IPCC 2014). The report confirms results from previous reports,

Trond G. Husby

trond.husby@pbl.nl

Elco E. Koks

elco.koks@vu.nl

1 Netherlands Environmental Assessment Agency (PBL), Bezuidenhoutseweg 30, 2594 AV Den Haag, The Netherlands

2 Institute for Environmental Studies (IVM), VU University Amsterdam, De Boelelaan 1087, $1081 \mathrm{HV}$ Amsterdam, The Netherlands 
stating that climate change, if left unchecked, will likely inflict serious economic damage across the globe. One of the key risks of climate change is the possibility of future increases in the frequency or severity of disasters. Models which translate physical disaster impacts into economic damage provide valuable inputs to policy makers, allowing for a comparison between the benefits and costs of reducing risks. It is, however, well known that individuals respond and adapt to environmental changes such as increasing risk (Leeuw 2008). Such responses may in turn have an impact on estimated disaster losses. It is therefore increasingly argued that models used for policy analysis need to incorporate adaptive human responses to the uncertainties and risks associated with a changing climate (Palmer and Smith 2014).

Extreme weather events can trigger household migration (Black et al. 2011a). For example, according to recent census numbers the population of New Orleans has still not recovered to pre-Katrina levels (Fussell et al. 2014). Such massive changes in the spatial distribution of people have large impacts on housing, labour and product markets in both origin and destination region. Ripple effects in the aftermath of disasters events affect agents, sectors and regions not directly affected by the events. Shortage of labour supply and lower demand for products in disaster struck regions can lead to inflated total losses in affected regions, while large amounts of displaced households can lead to housing shortages and put pressure on welfare systems in destination regions. As such, household responses in the aftermath of disasters are an important transmitter of such ripple effects.

Obtaining reliable empirical estimates of the magnitude of economy-wide disaster losses is challenging. Macroeconomic variables move together, often without any clear causal direction. Therefore, economy-wide effects are usually estimated with macroeconomic models such as input-output (IO) and computable general equilibrium (CGE) models (Okuyama and Santos 2014). Both of these models describe the economy as a set of interlinked equations, where agents and sectors are linked with each other through monetary flows of services and goods. Although IO and CGE models differ significantly in terms of structure and underlying assumptions, they share common strengths which make them suitable for the modelling of indirect effects. The rich details of flows of goods and services in IO and CGE models allow for an analysis of how disaster effects spread from one sector to another. Furthermore, both these types of models are calibrated on data coherent with national accounts.

While IO and CGE models are rich in details on the production side of the economy, they are often criticised for lack of details or for unrealistic assumptions regarding individual household behaviour (Scrieciu et al. 2013). One of these assumptions is that interactions between individual agents have no effects on aggregate variables. We argue that this assumption limits the ability of these models to capture household migration under disaster risk. Firstly, household decisions in the context of natural disasters are likely subject to a large degree of risk and uncertainty. When confronted with choices involving uncertainty and risk, humans often rely on either intuitive thinking or the opinion of others (Safarzynska et al. 2013). Secondly, the literature investigating the growth impacts of disasters often finds contradictory results (Cavallo et al. 2013), suggesting the existence of multiple equilibria. Multiple equilibria could arise, for example, through network effects in the supply chain (Todo et al. 2015), or through amplification processes leading to increases in public concern (Kasperson et al. 1988).

Agent-based models (ABMs) could potentially be used to address the limitations above. ABMs are bottom-up models, focusing on how system properties emerge through the interactions of heterogeneous individual agents (Grimm et al. 2006). ABMs have recently been used to study household migration under climate change (Cai et al. 2013; Smith 2014; 
Kniveton et al. 2012). The take-home message from this literature is that migration occurs through a chain of causalities between climatic and macroeconomic drivers as well as interactions through social networks. Although ABMs seem promising for modelling specific phenomena such as migration, their relatively ad hoc specification of the macroeconomy could limit their usefulness for policy analysis. In order to include realistic household behaviour in models used for disaster impact analysis, we suggest combining IO and CGE models with elements from ABMs.

In this paper, we discuss the limitations of IO and CGE models in representing household migration under disaster risk. Although several IO and CGE models consider endogenous labour market migration (Anas and Liu 2007; Sastry 1992), we argue that these models suffer from limitations in describing migration in the context of disaster risk, which is likely influenced by behavioural responses to risk. As a motivation for the discussion, we review important aspect of households' decision-making under risk and uncertainty. We finally discuss how ABMs could be combined with IO and CGE models in order to improve the representation of household migration in models used for disaster risk analysis. $^{1}$

The paper is structured as follows. In Sect. 2, the economics of natural disasters and household migration in the context of risk and uncertainty are being discussed. Section 3 gives a short description of IO and CGE models as well as their limitations. Section 4 gives an overview of ABMs and discusses how ABMs could be combined with IO or CGE models for disaster impact analysis. Section 4 concludes.

\section{The economics of natural disasters}

\subsection{Concepts and terminology}

In the economic literature, losses are often referred to as costs (Kousky and Walls 2014), and for the purposes of this paper, losses and costs are treated as synonyms while disaster effects and disaster impacts will be used interchangeably. In this respect, impacts and effects can be both positive and negative, whereas losses and costs are assumed to be always negative. In line with standard welfare economics, costs should represent the value of resources used/lost where value is measured in prices reflecting the resource's most efficient use. Accounting principles determine which costs should be included and which costs should not be counted as losses. Here, a distinction is usually made between stocks and flows - the former representing a certain quantity at a certain point in time and the latter services or outputs of stocks over time. Business interruptions are typically measured in terms of flows. Flow measures are often more suitable in disaster impact analysis, among other reasons because they more readily describe indirect effects (Rose 2004). ${ }^{2}$

\footnotetext{
${ }^{1}$ For a more extensive review of models on disaster impacts see Okuyama and Santos (2014). For a review of the empirical literature on climate change related migration see Klaiber (2014) and for a review of modelling of migration in the context of climate change, see McLeman (2013). We limit the discussion to the most prevalent models within disaster impact analysis, leaving out studies investigating the economic effects disasters using other types of macroeconomic models (Barro 2009, 2013; Martin and Pindyck 2014). For a general review on economic effects of climate change, including labour market impacts, see Dell et al. (2014).

${ }^{2}$ For clarification: stock losses can be interpreted as asset losses due to a disaster. In the engineering literature, asset losses are often referred to as "direct damage". Flow losses, on the other hand, can be
} 
Furthermore, a distinction is made in macroeconomics between short-run and long-run effects - the former corresponding roughly to time periods up to three years and the latter to time periods beyond that (Cavallo and Noy 2009). This distinction arises because of the convention in economics to treat certain inputs (usually capital) as fixed in the short run but variable in the long run. Short-run and long-run effects will usually differ significantly. For example, in the short run producers may well resort to new combinations of inputs in order to adapt to constraints of the supply of traditionally used inputs. In the long run, as supply lines are re-established, traditional input combinations may be used but some changes may persist for efficiency reasons. This latter phenomenon is sometimes referred to as a Schumpeterian "creative destruction" of disasters (Cuaresma et al. 2008).

Although definitions vary, disaster risk is commonly assumed to encompass the following three elements: hazard, vulnerability and exposure (IPCC 2014). The operational goal of disaster risk management is to reduce risk through combinations of measures aimed at any or several of these three elements.

Hazard refers to disaster-related events or biophysical impacts of such events (IPCC 2014). Traditionally disaster risk reduction has aimed at reducing hazard probability through structural measures such as building of dikes, dams and floodwalls.

Vulnerability is conceptualised as sensitivity or susceptibility to harm and lack of capacity to adapt (IPCC 2014). A distinction is often made between physical vulnerability and socioeconomic vulnerability of households. Many traditional risk assessments only evaluate physical vulnerability, i.e. the vulnerability of structures and goods (Filatova 2014). However, several studies highlight the importance of the socioeconomic dimension of vulnerability for disaster outcomes, where socioeconomic vulnerability is seen largely as a function of a household's sociodemographic status (Smith et al. 2006; Koks et al. 2015; Cutter et al. 2003). Several policy measures have been developed to reduce vulnerability, ranging from better evacuation routines and risk insurance to measures aimed at stimulating individual mitigation. Such individual mitigation measures are elevating houses, refitting the interior of buildings, purchasing sandbags as flood barriers and relocating movable equipment. Financial incentive mechanisms, such as insurance with risk-based premiums, can be introduced to stimulate the implementation of individual measures (Botzen et al. 2009). However, due to financial constraints and lack of information and incentives, vulnerable households may be less likely than other household types to implement such mitigation measures. The concentration of vulnerable households living in areas exposed to disasters is therefore an important determinant of losses (Mechler et al. 2014).

Exposure refers to the concentration of people, natural resources, and economic assets and services located in disaster-prone areas (IPCC 2014). Exposure is widely regarded as the main driver of increasing disaster losses during the past decades (IPCC 2012). Some studies argue that hazard reduction possibly inadvertently leads to an increase in exposure. For example, Husby et al. (2014) suggest that the wide-reaching dike building programmes in the Netherlands led to an increased concentration of population in areas potentially inundated in case of a flood. This phenomenon is referred to as the levee effect (Tobin 1995) or the safe development paradox (Burby 2006). Measures targeted at reducing exposure include land-use regulations, zoning and relocation of households and productive assets. As such, the migration of households after a flood could substantially change the

Footnote 2 continued

interpreted as output losses. In the engineering literature, output losses are referred to as "business interruption" or "indirect losses". 
exposure in an area to a future flood. Household locations are not only an important determinant of exposure-migration in the aftermath of a disaster is also a transmitter of disaster effects.

\subsection{Household migration and risk judgments}

The possibility of waves of migrating households as a consequence of either gradual effects of climate change or extreme weather events is a contentious topic which has recently received a great deal of attention (Warner 2010; Gemenne 2011; Black et al. 2011a, b, 2013; McLeman 2013; Obokata et al. 2014; Corbyn 2010). Population displacements have severe impacts on labour and housing markets in both origin and destination. Neglecting household responses in disaster impact analysis is therefore likely to lead to a biased estimate of the total disaster effect. One study suggests that neglecting human behaviour in flood risk assessment studies can result in a misestimation of future flood risk of a factor two (Haer et al. 2016). Vigdor (2008) argues that the massive population displacements following Katrina in 2005 shifted the city to a new equilibrium of housing prices and employment: the rampant destruction of houses, mainly in poor neighbourhoods of the city, implied a substantial negative supply shock in the lower end of the housing market, forcing poor households to leave New Orleans. As such, the economic aftermath of Katrina implied a decrease in average unemployment and an increase in average housing prices in New Orleans (Glaeser 2005). In addition, the displacement of thousands of poor households is likely to have had the opposite effect in destination regions for the migrating households (Fussell et al. 2014).

Although estimates vary, some studies suggest that the number of displaced households due to future climate change is likely to be substantial (Piguet 2010). One reason why estimates differ is the fact that household location decisions are complex phenomena likely to be affected by a range of non-climate related factors. In addition, it might also be the case that some of these other factors are indirectly affected by climate change, making it difficult to establish direct causal links between climate change and migration. Empirical studies typically seek to estimate one of the following two hypotheses: (i) to what extent do households migrate following changes in economic conditions due to climate change; (ii) to what extent do households respond directly to climate or safety as a consumption amenity. In the latter case, it is assumed that changes in climate or (perceived) hazard reduce the attractiveness of a location for households.

Examples of studies investigating the first hypothesis are Feng et al. (2010) and Feng et al. (2012) who examine linkages between climate variability, crop yields and migration among households in Mexico. The authors use an instrumental variable model to estimate the semi-elasticity of migration with respect to crop yields. Their results suggest that a 10 per cent decline in yield results in a 1.7 per cent decrease in population as a consequence of migration.

Examples of studies investigating the latter hypothesis can be found in the voluminous hedonic-pricing literature (Bin and Polasky 2004; Bin et al. 2008; Bin and Landry 2013; Atreya et al. 2013; Daniel et al. 2009b). These studies typically investigate whether disasters such as floods lead to house price disparities between risky and non-risky locations. This literature consistently finds that disasters have the effect of reducing the attractiveness of risky locations for prospective house buyers. Such housing price differentials suggest that disasters lead to an update in risk judgments in the aftermath of an event. In a metaanalysis of the hedonic-pricing literature, Daniel et al. (2009a) find that a 1 percentage 
point increase in the yearly probability of flooding is associated with, on average, a 0.6 per cent decrease in housing prices.

Marchiori et al. (2012) attempt to jointly estimate responses to climate from changes in economic conditions and changes in amenities. Using country-level panel data, the authors investigate the link between weather anomalies and migration in sub-Saharan Africa. Weather impacts migration both directly and indirectly through an interaction with the agricultural sector. The authors find evidence suggesting that both changes in economic conditions as well as changes in amenities had an effect on migration. They hypothesise that the amenity effect is related to health concerns or risk judgments.

However, a simple relationship between risk judgments and migration cannot simply be assumed (Hunter 2005). The literature suggests that households, when faced with lowprobability high-impact events, such as disasters, make decisions which deviate from what is considered rational (Barberis 2012). The separation of objective risk from individual risk judgments is one key insight of Prospect Theory (Tversky and Kahneman 1992; Kahneman and Tversky 1979). Prospect Theory suggests that people see outcomes in terms of gains or losses, attaching subjective weights to gains and losses. Probability weighting occurs over ranks of probabilities, not over untransformed probabilities. The implication of that weighting procedure is that low-probability/high-impact risk is overweighted and high probability/low-impact risk is underweighted (Camerer and Kunreuther 1989). Tversky and Kahneman (1973) do, however, suggest that people are likely to overestimate risks with which they have some familiarity and ignore risks that are unfamiliar. Translating availability heuristic to the case of flooding, households will ignore flood risk until a flood actually happens, after which they will attach a disproportional weight to the likelihood of a new flood.

Furthermore, predicting and assessing public reactions to events are complicated by the fact that collective risk judgments bear signs of being self-organising processes. The Social Amplification of Risk Framework suggests that collective risk judgments are amplified as (possibly biased) opinions of individual agents flow from one individual to another (Kasperson et al. 1988). This theoretical framework emphasises that (i) opinions of individual agents are affected by opinions of other agents in their social network; (ii) individual level risk judgments are often polarised, with high and low judgments of the same hazard coexisting in the same population. Empirical evidence supports the existence of "bandwagon effects", where events-even non-disastrous ones-results in major public concern as a lack of information leads to repetition and distortion of opinions through media and social networks. Amplification effects are likely to become ever more important with the ongoing growth of mass media and communication technologies. The perceived risk associated with residing in one specific location can have an impact on households' location decisions. As such, in a context of increasing risk household location decisions could potentially be affected by this type of amplification effects.

\section{Macroeconomic modelling of disasters: current practice}

This section provides a short review of the most commonly applied models in disaster impact analysis, namely IO models and CGE models. Although these models are based on rather different assumption, the connection with data and the relatively simple structure of both IO and CGE models make both models useful for disaster impact analysis. 


\subsection{Input-output models}

Standard IO models are static linear models describing the economy through sets of interrelationships between sectors themselves (the producers) and others (the consumers). These interrelationships between sectors are driven by intermediate demand and come as a result of fixed production coefficients in each sector. Intermediate demand is determined by final demand. Final demand in itself consists of the demand from consumption of goods from households, governments and exports and investments. Due to these characteristics, IO models have been employed in analyses of how the effects of a disaster ripple through the economy (e.g. Hallegatte 2008; Okuyama 2004; Steenge and Bočkarjova 2007). Their simple representation of the economy makes them relatively easy to combine with models with more details on, for instance, the water-cycle (hydraulic models) (Rose 2004). Examples of these coupled models are Jonkman et al. (2008) and Koks et al. (2014). However, the fixed proportion production function (Leontief) in standard IO models rules out factor substitution within the production system, meaning that changes in relative prices has no effect on the economy. The lack of substitution possibilities in standard IO models generally results in inflated estimated disaster losses relative to losses estimated by CGE models (Koks et al. 2016).

The demand-driven characteristic of traditional IO models means that these models neglect eventual changes on the supply-side: the production form (i.e. technology) in different sectors is assumed to remain unchanged after the disaster strikes. Furthermore, producers and final consumers are restricted from importing inputs and consumption goods from non-affected suppliers (Hallegatte 2008). Omitting such mechanisms not only leads to inflated modelled disaster losses-it also reduces the realism of the model. To overcome some of these issues of traditional IO models, several hybrid models have been developed. Such hybrid models retain the simplicity of IO traditional models, while providing more flexibility as available in CGE modelling. Examples are the commonly used ARIO model (Hallegatte 2008) and the more recently developed models by Koks and Thissen (2016) and Oosterhaven and Bouwmeester (2016).

As argued above, an inherent limitation of standard IO models and current IO disaster impact models is the exogenous and rather simplistic representation of households (captured in the final demand). In the long history of IO modelling, such issues have been (partly) tackled by developing extended IO models and by endogenizing households in an IO model (Miyazawa 1976). This has allowed for more explicit demographic-economic interactions within the IO model. Some of these extensions have focused on migration. For instance, Beyers (1980) integrated a multiregional IO model with a demographic model to capture the combined effects of employment, income levels and migration. Another example is the study by Sastry (1992) who quantified, in detail, the effect of (elderly) migration on income, employment and earning levels for a single-region economy. An interesting recent example is the development of a spatial regional econometric input-output model (REIM), developed by Kim and Hewings (2012). By integrating a bottom-up approach into an IO, the authors are able to carry out a detailed analysis of the population in a specific regions. This bottom-up approach reveals the macroeconomic effects arising from specific local changes such as increased flood protection or changes in land-use policies.

\subsection{Computable general equilibrium models}

CGE models describe the macroeconomy as a circular flow of goods and services between sectors. In these models, representative households and firms choose their demand and 
supply for goods and services according to constrained optimisation problems, taking prices as given. Prices are determined by market equilibrium conditions. CGE models are therefore driven by changes in relative prices, rather than solely by changes in the quantities of goods (as IO models are). Hallegatte (2008) argues that the latter approach makes IO models superior to CGE models in the disaster context, while Rose and Guha (2004) are of the opposite opinion: relative price effects add economic details and relax the assumption of linearity, rather assuming increasing or decreasing returns to scale. This allows for incorporating input/import substitution, non-infinite supply elasticities and more realistic behavioural content and working of both factor and product markets (Rose 2004). As mentioned, CGE models are considered to yield "optimistic" results in terms of disaster losses-especially compared to IO models (Okuyama and Santos 2014). This is partly a result of the inherent adaptation in the models, achieved through factor substitution, and partly a result of the assumption that prices work in such a way as to balance demand and supply and to create incentives for production of the most needed goods and services (Hallegatte and Przyluski 2010).

CGE models have also been extended and further developed to be more suitable for disaster impact analysis. For instance, Rose and Liao (2005) have developed a CGE model, where they recalibrate the production function to account for resilience-both static and dynamic. The former type of resilience is incorporated in the specification of the production functions for individual industries, while dynamic resilience is modelled through changes to parameters. In order to make the model mimic the real world, parameters are calibrated using survey data. Also, a disaster may require additional constraints in the economy, particularly in the short-run. For example, there might well be restrictions on the movement of capital and labour in the aftermath of a crisis. Tsuchiya et al. (2007) develop a spatial CGE model to assess the economic impacts of infrastructure disruption. In spatial CGE models, the distance between agents in the economy is explicitly incorporated as a dimension. In order to incorporate additional constraints, the authors simulate the impact of certain links of the transportation network becoming disconnected. In the model, this results in higher transportation costs on the affected links, again leading to a new postdisaster equilibrium. Thus, this allows for a calculation of a new short-run equilibrium when capital and labour inputs are restricted on certain links, which again can be used to establish political priorities regarding which links to be strengthened (Tsuchiya et al. 2007).

Some studies have focused specifically on economic impacts from changes in demand in the aftermath of disasters. Rose and Oladosu (2008) explicitly model the impact of disasters on households' demand for goods and analyse the feedback effects on the economy. In another promising attempt of adding more details to the demand side, Giesecke et al. (2012) use survey data to obtain detailed information changes in risk perception in case of a terrorist attack in Los Angeles. Information about reductions in demand for goods produced in Los Angeles is fed into a CGE model used to assess the macroeconomic consequences of such an attack. The authors find that the inclusion of behavioural reactions lead to production losses up to 14 times the size of ordinary production losses. Several attempts have also been made at modelling decisions under risk and uncertainty in CGE models (Husby et al. 2016; Pratt et al. 2013). In these models, decisions under uncertainty are usually represented as mimicking actuarial calculations of risk.

Scholars within regional economics have developed CGE models to capture endogenous migration. Examples of such models are the RELU-TRAN (Anas and Liu 2007), RAEM (Ivanova et al. 2007) and RHOMOLO (Brandsma et al. 2014) (see Partridge (2010) and Giesecke and Madden (2013) for reviews of regional CGEs). Regional CGEs 
are mainly used to capture the regional effects of specific (national) government policies. In these models, labour migration occurs through spatial differences in utility levels, where utility is determined by consumption possibilities and by the flow of amenities. Prices and wages adjust until workers are indifferent between moving or staying at their current location (spatial equilibrium). Consequently, migration has important general equilibrium effects. For example, labour scarcity in a region pushes up wages and limit production possibilities within that region. Some regional CGE models also include several household types, where households differ in terms of skills and receive income according to their skill level and employment status (Anas and Liu 2007).

\subsection{Limitations of IO and CGE models in disaster impact analysis}

Recurring insider critiques include concerns regarding data quality, as well as questions related to technical limitations and interpretations of results (Albala-Bertrand 2013; Okuyama and Santos 2014). Additionally, one major challenge with these models is the calibration of used parameters, as data are scarce and often of poor quality. Sensitivity analyses have shown that results are often highly dependent on certain parameter values, in particular those governing the speed of reconstruction and adaptation characteristics (Koks et al. 2014). Problems with data availability often limit the level of detail in the analysis.

A common outsider critique against general equilibrium modelling regards the use of representative agents (Colander et al. 2008; Kirman 1992). In CGE models, optimisation problems are stated for and solved by one agent assumed to be representative for a whole population or groups of the population. One important reason behind the popularity of the representative agent approach is that it facilitates the aggregation of individual demand and supply curves. By abstracting from impacts on the aggregate outcome arising from interactions between individual agents within the representative group, CGE models become solvable and tractable: modern CGE models are likely far too complex to be solved for millions of heterogeneous interacting agents. However, the representative agent approach imposes rather strong, and in some contexts unrealistic, assumptions on individual behaviour. It is, for example, implicitly assumed that agent has access to all information relevant to their optimisation problem. This assumption entails that information such as the probability distribution of disasters is known by agents and is relevant for their decision-making. As mentioned above, the context of disaster risk is characterised by lack of information or behavioural biases in the interpretation of information. Individual risk judgments may well be shaped by the exchange of information between individuals. By determining a representative group of agents, CGE models effectively rule out interaction between members within one group, such as the spread of risk opinions between individual members. Potential effect on aggregate labour supply from such interactions is by assumption ignored.

A related critique regards the limited description of the dynamic process of reaching equilibrium (Hallegatte and Ghil 2008): in CGE models it is implicitly assumed that equilibrium prices are reached through tatonnement - an iterative auction process between sellers and buyers on a market. However, some researchers suggest that the set of prices obtained by CGE models represents just one of many possible sets of prices (Gintis 2007). Discarding the assumption of representative agents, it is likely that partly private information and decision making based on copying and thumb rules can give rise to a wide range of equilibrium outcomes. As such, even if economic fundamentals and preferences remain unaltered after an event, changes in beliefs as well as interaction effects could be a source of multiple equilibria (Dosi and Egidi 1991; Dosi 1990). This is particularly 
important in a context of natural disasters: the likely impact of individual beliefs and interaction effects on migration decisions could result in several candidate equilibrium populations.

\section{Household migration in disaster impact models: way forward}

Above we argued that households' location decisions are likely to be affected by individual risk judgments and public concern. Although several IO and CGE models incorporate endogenous labour migration, they suffer from limitations in capturing elements which bear signs of self-organising processes. We suggest that some of the limitations of IO and CGEs can be addressed by combining these models with ABMs.

\subsection{An alternative to optimisation models: ABMs}

ABMs are increasingly promoted as an alternative to more traditional economic tools (An 2012). ABMs relax assumptions regarding representative agents and decision-making based on optimisation. In ABMs, behaviour is represented as decision rules which map agents' observations on to actions. This feature gives a modeller the flexibility to choose whatever he or she deems to be realistic decision rules. Furthermore, in ABMs the economy is conceptualised as a complex system, characterised by interacting agents and emergent properties, meaning that properties of the system arise from interactions rather than being properties of the agents themselves (Tesfatsion and Judd 2006).

In general, most non-trivial real-world systems are likely to exhibit nonlinear dynamics, and it is increasingly argued that models used to study real-world phenomena must allow for complexity (Battiston et al. 2016). Some of the characteristics of ABMs make them attractive for investigating crises. Bounded rationality, endogenous out-of-equilibrium dynamics and direct interactions are important drivers of asset bubbles, network resilience, detection of tipping points and financial accelerator dynamics (Fagiolo and Roventini 2012). The flexible representation of behavioural rules makes ABMs suitable for studying learning and adaptive behaviour. For example, financial bubbles can be explained by agents switching to better-performing heuristics: ABMs can be used to show how persistent deviations from equilibrium and boom-and-bust patterns arise from trend-following and herding behaviour (Hommes 2013).

\subsection{Household migration in ABMs}

One of the most influential ABMs used to investigate household migration is Thomas Schelling's neighbourhood segregation model, also called the checkerboard model (Schelling 1978, 1969). This model shows how a relatively small change, i.e the move of one agent, sets off bandwagon effects leading to full segregation of neighbourhoods. ABMS have been applied to a wide range of research topics, including risk on land and housing markets (Geanakoplos et al. 2012; Putra et al. 2015; Filatova et al. 2009), evaluation of flood protection measures (Haer et al. 2016; O'Connell and O'Donnell 2013; Sobiech 2013; Brouwers and Boman 2011) and distributional effects of natural disasters (Naqvi and Rehm 2014). A number of authors have investigated household migration in the context of climate change using ABMs (Cai et al. 2013; Smith 2014; Kniveton et al. 2012). Kniveton et al. (2012) develop a model to explore how climate and demographic 
change combine to influence migration to and from Burkina Faso. The main goal of the authors is to identify the relative contribution of a range of factors potentially affecting migration decisions. Migration flows are governed by an agent-specific probability of migration between two regions, determined by personal attributes and rainfall variability. Rainfall variability is used as a proxy for all types of climatic influences on migration. An agent's attitude towards migration is also affected by networked peers: an agent's probability of migration is adjusted for the proportion of linked agents who have already migrated. Simulation exercises illustrate how migration increases in drier conditions. However, migration occurs through a complex chain of causalities between rainfall, population growth and social networks. The isolated impact of climate factors remains non-significant.

In Kniveton et al. (2012) risk judgment and the formation of public concern is assumed to play a role for migration behaviour but it is not modelled explicitly. The dynamics of the formation of collective opinions have been studied in a literature using stylised mathematical simulations models (Sznajd-Weron and Sznajd 2000; Weisbuch et al. 2002; Deffuant et al. 2000, 2002; Hegselmann and Krause 2002; Castellano et al. 2009; Quattrociocchi et al. 2014; Moussaïd 2013), for instance, develops an ABM of opinion dynamics addressing how the collective opinion of risk such as attitude towards climate change is formed through exchanges of individual risk judgments. In this model, agents are initially exposed to the same information through mass media, but agents differ in terms of probability to search for new information. Individual opinions are, in each time-step of the model, updated with a weighted opinion of a randomly chosen neighbour in a social network. Numerical simulations reveal the key role of social interactions: if the social interactions are low there is little updating and few alterations to the initial distribution of opinions. When social interactions increase, there is an emerging correlation of opinions between neighbours on the social network. For very high levels of social interactions, a consensus regarding risk emerges. Acemoglu et al. (2013) use an opinion dynamics model to analyse the impact on risk judgments from the presence of extremist opinions. Extremists are conceptualised as agents holding extreme opinions who do not change their opinion through the interaction with other agents. The combination of a large share of extremists and a high degree of connectivity between agents in a population can have the effect of pushing up the consensus risk judgment. In this model, influences from other agents' opinions can be a source of multiple equilibria.

\subsection{Combining CGE and IO models with ABMs for disaster impact analysis}

As argued throughout this article, despite recent developments in IO and CGE modelling, these models are limited in capturing any impacts from interactions between individual agents. However, the tractability, transparency and fairly simple structure of these models, allows them to be combined with other models. IO models, for instance, have a long history in being combined and extended for numerous purposes. Models have been extended to better incorporate household behaviour and environmental externalities (e.g. carbon and water) (Zhao et al. 2009; Wiedmann et al. 2006). Another good example of a coupled IO and bottom-up model is the TransNIEMO model, where a multiregional IO model and a transportation network model are combined, which allows for the assessment of the economic consequences of a disaster on a major element of the highway network (Park et al. 2011). In other words, IO models prove to be a good starting point in connecting an aggregate economic system with a fine level of detail in interactions between economic agents. A recent example of an ABM coupled with an IO model is the study of 
Oliva et al. (2010). Here the authors aim to capture the infrastructure interdependencies by decomposing each infrastructure into a set of interconnected elements and considering the exchange of resources between them. As such, while the IO model only allows for interaction at a high level of abstraction, the ABM coupling refined this by allowing for the modelling of interdependencies with a much finer granularity.

Similarly, CGE models contain a number of promising connection points with an ABM, for example, parameters that describe behavioural processes, labour augmenting productivity or production technology. It is well known that these parameters shift over time (Go et al. 2016). These shifts could be governed by dynamics arising within an ABM. The integration of CGE models and ABMs has been discussed in some research fields-most notably within land use science (e.g. Berger and Troost 2014; Rounsevell et al. 2014). However, we are not aware of any studies that have carried out disaster impact analysis using an IO or CGE model combined with an ABM. The literature on combining topdown/bottom-up models provides some concrete suggestions on how IO and CGE models could be combined with ABMs (Böhringer and Rutherford 2008; Hourcade et al. 2006).

One approach-hard linking or a complete integration-emphasises the overall economic consistency and makes use of a single integrated modelling framework. In such a formulation, outputs from the ABM would have to be part of the solution algorithm in the IO or CGE. Böhringer and Rutherford (2008) suggest that hard linking bottom-up and topdown models could be accomplished by solving the combined CGE and IO as a mixed complementarity problem. The mixed complementarity approach, frequently used to solve CGE models, entails establishing a system of weak inequalities and complementarity between decision variables and market equilibrium. Böhringer and Rutherford (2008) show how bottom-up and top-down models can be solved iteratively: in order to solve the topdown economic equilibrium model, complementarity methods are used, while quadratic programming is applied to solve the bottom-up model. One possibility in this case would be to let agent's decisions to buy a house be governed by an ABM in which the housing market decisions include risk judgments as well. Wages and prices for goods and services, both determinant of a household consumption budget, could be determined in a CGE model.

Hard linking is likely to be a challenging option, potentially leading to difficulties with convergence in the IO or CGE. To the best of our knowledge, the literature of disaster impact analysis contains no examples of studies attempting to hard link IO or CGEs with ABMs. A second option-soft linking - entails connecting independently developed IO or CGE models and ABMs through somewhat more limited data exchange between the two models. For example, the aggregate demand for housing in a CGE or IO model could be determined within an $\mathrm{ABM}$ of the housing market. Differences in behavioural assumptions and accounting principles across the models can potentially result in problems related with overall coherence.

An example of a soft-linked model CGE-ABM is Husby (2016, ch. 7) who uses an $\mathrm{ABM}$ of opinion dynamics to analyse the impact of public concern on disaster losses predicted by a Spatial CGE model. Increasing public concern reduces the utility flow from amenities in the disaster struck region, making this region less attractive as a place of residence. Output from the ABM enters household location decisions which are modelled in the recursive dynamics structure of the CGE. As such, the ABM helps determining household relocations in-between time periods in the CGE. The public concern generated by the disaster and the ensuing relocation reduces labour supply in the disaster-affected areas and exacerbates macroeconomic losses from the disaster. 
A key message from the model exercise in Husby (2016, ch. 7) is that individual uncertainty and interaction effects leading to amplification of public concern have substantial quantitative impacts on modelled disaster losses. In fact, for one specific level of capital destruction, there are several possible equilibrium labour supply responses and consequently multiple equilibria in modelled disaster losses. This result resonates with the empirical literature on growth effects of disasters. Combined CGE-ABM can therefore allow for an investigation of how individual uncertainty and interactions can lead to predicted multiple equilibria in disaster losses.

Despite the attractive features of combined macroeconomic models and ABMs, there are also substantial challenges in developing and employing such models. A first challenge concerns the technical implementation of the integration or of the data exchange. As mentioned above, the rich literature on combining top-down and bottom-up models provide suggestions on how to overcome the technical challenges. A second, related, challenge is ensuring the overall consistency of the combined model. Differences in aggregation levels, in units of measurement or in time scale between the models, may result in difficulties when using outputs from the $A B M$ as inputs to the macroeconomic model. A third challenge, particularly relevant for hard linked models, is that a macroeconomic model will be unsolvable unless there are bounds on the outcomes of the ABM. The use of the combined model may therefore rule out a number of potentially plausible outcomes of the ABM.

\section{Conclusions and recommendations for future research}

The likely future increases in disaster risk have recently gained a great deal of attention in research and policy. Quantitative estimates of disaster impacts provide useful inputs for policy makers involved in developing responses to the threat posed by this increasing risk. One important side effect of disaster risk is household migration-essentially a form of adaptive behaviour on the household side. Large changes in the spatial distribution of labour supply as well as in the demand for goods and services are likely to be an important determinant of estimated disaster losses. Household migration is therefore an important component in models used for disaster impact analysis.

In this article, we have discussed some of the limitations of these models in representing household migration under disaster risk. More specifically, individual risk judgments and public concern are likely formed and shaped through interactions between individual agents with heterogeneous beliefs. Such interaction effects could possibly lead to multiple equilibria which are not easily captured within IO and CGE models. We suggest that these limitations could potentially be addressed by combining IO and CGE models with ABMs.

Throughout the paper we have sought to highlight the relative strengths of both types. IO models offer simplicity and transparency, yet their high level of details on sectoral and regional interlinkages makes this model type powerful tools in disaster impact analysis. Relative to IO models, CGE models add more detail regarding the economic behaviour of agents, including reactions to price changes. In spite of the fact that CGE models occasionally are subject to "black box" critique, CGEs are simple enough to be easily connected to other models. Although IO and CGE models are based on rather different assumptions and are often seen as competing modelling traditions, they are highly complementary in disaster impact analysis. Researchers are also exploring the added value of carrying out joint analyses with IO and CGE models (Koks et al. 2016; Hu et al. 2014). For 
all these reasons, it is expected that IO and CGE models are likely to remain among the most important tools used for disaster impact analysis at least in the near future.

In addition, ABMs developed for studying microeconomic phenomena such as the impact of flood risk on migration decisions tend to suffer from shortcomings in accounting for price distortions, economy-wide interactions and income effects (Böhringer and Rutherford 2008). Some authors argue for abandoning the macroeconomic models currently in use, including IO and CGE models, in favour of fully fledged macroeconomic ABMs (Farmer and Foley 2009). However, although macroeconomic ABMs are highly informative in exploring phenomena such as multiple equilibria or out-of-equilibrium dynamics, it is likely that macroeconomic ABMs require introducing a large number of restrictions to reach stability (Mandel 2012). In addition, the somewhat ad hoc specification of parameters is an inherent feature of all models that try to explain observed outcomes through partly unobserved mechanisms. ABMs try to explain aggregate phenomena through largely unobserved, micro-level interactions. The extreme flexibility regarding the introduction of parameters means that ABMs have virtually infinite degrees of freedom (although methods are being developed to pin down the value of critical parameters (e.g. Grazzini and Richiardi 2015)). Most importantly, fully fledged macroeconomic ABMs developed so far have not been widely used for concrete policy advice (Battiston et al. 2016; Colander et al. 2008). It is therefore difficult to judge their track record. Finally, the introduction of additional assumptions and extra layers of complexity can render ABMs vulnerable to black box criticism, where only a small number of practitioners will be able to use the models in a meaningful way. In comparison, the usage of tractable models such as IO and CGEs entails a less steep learning curve. Instead of discarding the models currently in use, we suggest a step-wise improvement: by combining the existing models with ABMs, the rigorous structure of IO and CGE models set limits on outcomes from the $\mathrm{ABM}$, while the ABM adds realistic behavioural features to the IO and CGEs.

Acknowledgements This research was carried out and funded as part of the Dutch Knowledge for Climate Research Programme (Theme 8), the EU FP7 TURAS project (Grant Agreement No: 282834), the ENHANCE project (Grant Agreement No: 308438). The paper benefitted substantially from comments by six anonymous reviewers, Henri L.F. de Groot and Marjan Hofkes.

Open Access This article is distributed under the terms of the Creative Commons Attribution 4.0 International License (http://creativecommons.org/licenses/by/4.0/), which permits unrestricted use, distribution, and reproduction in any medium, provided you give appropriate credit to the original author(s) and the source, provide a link to the Creative Commons license, and indicate if changes were made.

\section{References}

Acemoglu D, Como G, Fagnani F, Ozdaglar A (2013) Opinion fluctuations and disagreement in social networks. Math Oper Res 38(1):1-27

Albala-Bertrand JM (2013) Disasters and the networked economy. Routledge, New York

An L (2012) Modeling human decisions in coupled human and natural systems: review of agent-based models. Ecol Model 229:25-36

Anas A, Liu Y (2007) A regional economy, land use, and transportation model (RELU-TRAN). J Reg Sci 47(3):415-455

Atreya A, Ferreira S, Kriesel W (2013) Forgetting the flood? An analysis of the flood risk discount over time. Land Econ 89(4):577-596

Barberis NC (2012) Thirty years of prospect theory in economics: a review and assessment. NBER Working Paper 18621, National Bureau of Economic Research, Cambridge

Barro RJ (2009) Rare disasters, asset prices, and welfare costs. Am Econ Rev 99(1):243-264 
Barro RJ (2013) Environmental protection, rare disasters, and discount rates. NBER Working Paper 19258, National Bureau of Economic Research, Cambridge

Battiston S, Farmer JD, Flache A, Garlaschelli D, Haldane AG, Heesterbeek H, Hommes C, Jaeger C, May R, Scheffer M (2016) Complexity theory and financial regulation. Science 351(6275):818-819

Berger T, Troost C (2014) Agent-based modelling of climate adaptation and mitigation options in agriculture. J Agric Econ 65(2):323-348

Beyers WB (1980) Migration and the development of multiregional economic systems. Econ Geogr 56(4):320-334

Böhringer C, Rutherford TF (2008) Combining bottom-up and top-down. Energy Econ 30(2):574-596. doi:10.1016/j.eneco.2007.03.004

Bin O, Landry CE (2013) Changes in implicit flood risk premiums: empirical evidence from the housing market. J Environ Econ Manag 65(3):361-376

Bin O, Polasky S (2004) Effects of flood hazards on property values: evidence before and after Hurricane Floyd. Land Econ 80(4):490-500

Bin O, Kruse JB, Landry CE (2008) Flood hazards, insurance rates, and amenities: evidence from the coastal housing market. J Risk Insur 75(1):63-82

Black R, Adger WN, Arnell NW, Dercon S, Geddes A, Thomas D (2011a) Migration and global environmental change. Glob Environ Change 21

Black R, Bennett SR, Thomas SM, Beddington JR (2011b) Climate change: migration as adaptation. Nature 478(7370):447-449

Black R, Adger WN, Arnell NW (2013) Migration and extreme environmental events: new agendas for global change research. Environ Sci Policy 27:S1-S3. doi:10.1016/j.envsci.2012.09.010

Botzen WJ, Aerts JC, van den Bergh JC (2009) Willingness of homeowners to mitigate climate risk through insurance. Ecol Econ 68(8):2265-2277

Brandsma A, Kancs d, Persyn D (2014) Modelling migration and regional labour markets: an application of the new economic geography model RHOMOLO. J Econ Integr 29(2):372-406. http://www.jstor.org/ stable/23723860

Brouwers L, Boman M (2011) A computational agent model of flood management strategies. Comput Methods Agric Res Adv Appl 296-307

Burby RJ (2006) Hurricane Katrina and the paradoxes of government disaster policy: bringing about wise governmental decisions for hazardous areas. Ann Am Acad Polit Soc Sci 604(1):171-191. doi:10. $1177 / 0002716205284676$

Cai R, Oppenheimer M (2013) An Agent-based model of climate-induced agricultural labor migration. In: 2013 Annual meeting, August 4-6, 2013, Washington, DC. Agricultural and Applied Economics Association

Camerer CF, Kunreuther H (1989) Decision processes for low probability events: policy implications. J Policy Anal Manag 8(4):565-592

Castellano C, Fortunato S, Loreto V (2009) Statistical physics of social dynamics. Rev Mod Phys 81(2):591-646. doi:10.1103/RevModPhys.81.591

Cavallo E, Noy I (2009) The economics of natural disasters: a survey. RES Working Papers 4649, InterAmerican Development Bank

Cavallo E, Galiani S, Noy I, Pantano J (2013) Catastrophic natural disasters and economic growth. Rev Econ Stat 95(5):1549-1561

Colander D, Howitt P, Kirman A, Leijonhufvud A, Mehrling P (2008) Beyond DSGE models: toward an empirically based macroeconomics. Am Econ Rev 98(2):236-240. doi:10.1257/aer.98.2.236

Corbyn Z (2010) Mexican 'climate migrants' predicted to flood US. Nature News, Published online 26 July 2010. doi:10.1038/news.2010.375

Cuaresma J, Hlouskova J, Obersteiner M (2008) Natural disasters as creative destruction: evidence from developing countries. Econ Inq 46(2)

Cutter SL, Boruff BJ, Shirley WL (2003) Social vulnerability to environmental hazards. Soc Sci Q 84(2):242-261

Daniel VE, Florax RJ, Rietveld P (2009a) Flooding risk and housing values: an economic assessment of environmental hazard. Ecol Econ 69(2):355-365

Daniel VE, Florax RJ, Rietveld P (2009b) Floods and residential property values: a hedonic price analysis for the Netherlands. Built Environ 35(4):563-576

Deffuant G, Neau D, Amblard F, Weisbuch G (2000) Mixing beliefs among interacting agents. Adv Complex Syst 3(1):87-98. doi:10.1142/S0219525900000078

Deffuant G, Amblard F, Weisbuch G, Faure T (2002) How can extremism prevail? A study based on the relative agreement interaction model. J Artif Soc Soc Simul 5(4) 
Dell M, Jones BF, Olken BA (2014) What do we learn from the weather? The new climate-economy literature. J Econ Lit 52(3):740-798. doi:10.1257/jel.52.3.740

Dosi G (1990) Finance, innovation and industrial change. J Econ Behav Org 13(3):299-319. doi:10.1016/ 0167-2681(90)90003-V

Dosi G, Egidi M (1991) Substantive and procedural uncertainty. J Evol Econ 1(2):145-168. doi:10.1007/ BF01224917

Fagiolo G, Roventini A (2012) Macroeconomic policy in DSGE and agent-based models. Revue de l'OFCE 5:67-116

Farmer JD, Foley D (2009) The economy needs agent-based modelling. Nature 460(7256):685-686

Feng S, Krueger AB, Oppenheimer M (2010) Linkages among climate change, crop yields and Mexico-US cross-border migration. Proc Natl Acad Sci USA 107(32):14257-14262. doi:10.1073/pnas.1002632107

Feng S, Oppenheimer M, Schlenker W (2012) Climate change, crop yields, and internal migration in the United States. Working Paper 17734, National Bureau of Economic Research, Cambridge. doi:10. $3386 / w 17734$

Filatova T (2014) Market-based instruments for flood risk management: a review of theory, practice and perspectives for climate adaptation policy. Environ Sci Policy 37:227-242. doi:10.1016/j.envsci.2013. 09.005

Filatova T, van der Veen A, Parker DC (2009) Land market interactions between heterogeneous agents in a heterogeneous landscape-tracing the macro-scale effects of individual trade-offs between environmental amenities and disamenities. Can J Agric Econ 57(4):431-457

Fussell E, Curtis KJ, de Waard J (2014) Recovery migration to the City of New Orleans after Hurricane Katrina: a migration systems approach. Popul Environ 35(3):305-322. doi:10.1007/s11111-014-0204-5

Geanakoplos J, Axtell R, Farmer JD, Howitt P, Conlee B, Goldstein J, Hendrey M, Palmer NM, Yang CY (2012) Getting at systemic risk via an agent-based model of the housing market. Am Econ Rev 102(3):53-58. doi:10.1257/aer.102.3.53

Gemenne F (2011) Why the numbers don't add up: a review of estimates and predictions of people displaced by environmental changes. Glob Environ Change 21:S41-S49. doi:10.1016/j.gloenvcha.2011.09.005

Giesecke JA, Madden JR (2013) Regional Computable General Equilibrium Modeling. In: Dixon PB, Jorgenson DW (eds) Handbook of Computable General Equilibrium Modeling SET, Vols. 1A and 1B. Elsevier, pp 379-475. doi:10.1016/B978-0-444-59568-3.00007-9

Giesecke JA, Burns WJ, Barrett A, Bayrak E, Rose A, Slovic P, Suher M (2012) Assessment of the regional economic impacts of catastrophic events: CGE analysis of resource loss and behavioral effects of an RDD attack scenario. Risk Anal 32(4):583-600. doi:10.1111/j.1539-6924.2010.01567.x

Gintis H (2007) The dynamics of general equilibrium. Econ J 117(523):1280-1309. doi:10.1111/j.14680297.2007.02083.x

Glaeser EL (2005) Should the government rebuild New Orleans, or just give residents checks? Econo Voice 2(4):1-7

Go DS, Lofgren H, Ramos FM, Robinson S (2016) Estimating parameters and structural change in cge models using a Bayesian cross-entropy estimation approach. Econ Model 52:790-811

Grazzini J, Richiardi M (2015) Estimation of ergodic agent-based models by simulated minimum distance. J Econ Dyn Control 51:148-165

Grimm V, Berger U, Bastiansen F, Eliassen S, Ginot V, Giske J, Goss-Custard J, Grand T, Heinz SK, Huse G, Huth A, Jepsen JU, Jörgensen C, Mooij WM, Müller B, Pe'er G, Piou C, Railsback SF, Robbins AM, Robbins MM, Rossmanith E, Rüger N, Strand E, Souissi S, Stillman RA, VabøR Visser U, DeAngelis DL (2006) A standard protocol for describing individual-based and agent-based models. Ecol Model 198(1-2):115-126. doi:10.1016/j.ecolmodel.2006.04.023

Haer T, Botzen W, Moel H, Aerts JC (2016) Integrating household risk mitigation behavior in flood risk analysis: an agent-based model approach. Risk Anal. doi:10.1111/risa.12740

Hallegatte S (2008) An adaptive regional input-output model and its application to the assessment of the economic cost of Katrina. Risk Anal 28(3):779-799. doi:10.1111/j.1539-6924.2008.01046.x

Hallegatte S, Ghil M (2008) Natural disasters impacting a macroeconomic model with endogenous dynamics. Ecol Econ 68(1-2):582-592

Hallegatte S, Przyluski V (2010) The economics of natural disasters: concepts and methods. Policy Research Working Paper Series 5507, The World Bank, Washington, DC

Hegselmann R, Krause U (2002) Opinion dynamics and bounded confidence models, analysis, and simulation. J Artif Soc Soc Simul 5(3)

Hommes C (2013) Behavioral rationality and heterogeneous expectations in complex economic systems. Cambridge University Press, Cambridge

Hourcade JC, Jaccard M, Bataille C, Ghersi F (2006) Hybrid modeling: new answers to old challenges. Introduction to the Special Issue of" The Energy Journal”. Energy J 1-11 
Hu A, Xie W, Li N, Xu X, Ji Z, Wu J (2014) Analyzing regional economic impact and resilience: a case study on electricity outages caused by the 2008 snowstorms in southern China. Nat Hazards 70(2):1019-1030. doi:10.1007/s11069-013-0858-9

Hunter LM (2005) Migration and environmental hazards. Popul Environ 26(4):273-302

Husby TG (2016) Economic impacts of behavioural responses to flood risk: exploring general equilibrium effects using micro-level insights. PhD thesis, Institute for Environmental Studies (IVM), VU University, Amsterdam. Available at http://dare.ubvu.vu.nl/handle/1871/54109

Husby TG, de Groot HL, Hofkes MW, Dröes MI (2014) Do floods have permanent effects? Evidence from the Netherlands. J Reg Sci 54(3):355-377

Husby TG, Mechler R, Jongman B (2016) What if Dutch investors started worrying about flood risk? Implications for disaster risk reduction. Reg Environ Change 16(2):565-574

IPCC (2012) A Special Report of Working Groups I and II of the Intergovernmental Panel on Climate Change. In: Field CB, Barros V, Stocker TF, Qin D, Dokken DJ, Ebi KL, Mastrandrea MD, Mach KJ, Plattner GK, Allen SK, Tignor M, Midgley PM (eds) Managing the Risks of Extreme Events and Disasters to Advance Climate Change Adaptation, University Press, Cambridge, UK, and New York, NY, USA

IPCC (2014) Climate change 2014: Impacts, adaptation, and vulnerability. part A: global and sectoral aspects. Contribution of working group II to the fifth assessment report of the intergovernmental panel on climate change. University Press, Cambridge, UK, and New York, NY, USA, pp 1-32

Ivanova O, Heyndrickx C, Spitaels K, Tavasszy L, Manshanden W, Snelder M, Koops O (2007) RAEM: version 3.0. First report, Transport \& Mobility Leuven, Leuven

Jonkman SN, Bockarjova M, Kok M, Bernardini P (2008) Integrated hydrodynamic and economic modelling of flood damage in the Netherlands. Ecol Econ 66(1):77-90. doi:10.1016/j.ecolecon.2007.12.022

Kahneman D, Tversky A (1979) Prospect theory: an analysis of decision under risk. Econometrica 47(2):263-291

Kasperson RE, Renn O, Slovic P, Brown HS, Emel J, Goble R, Kasperson JX, Ratick S (1988) The social amplification of risk: a conceptual framework. Risk Anal 8(2):177-187. doi:10.1111/j.1539-6924. 1988.tb01168.x

Kim JH, Hewings GJ (2012) Integrating the fragmented regional and subregional socioeconomic forecasting and analysis: a spatial regional econometric input-output framework. Ann Reg Sci 49(2):485-513

Kirman AP (1992) Whom or what does the representative individual represent? J Econ Perspect 6(2):117-136

Klaiber HA (2014) Migration and household adaptation to climate: a review of empirical research. Energy Econ 46:539-547

Kniveton DR, Smith CD, Black R (2012) Emerging migration flows in a changing climate in dryland Africa. Nat Clim Change 2(6):444-447

Koks EE, Thissen M (2016) A multiregional impact assessment model for disaster analysis. Econ Syst Res 28(4):429-449

Koks EE, Bockarjova M, de Moel H, Aerts JC (2014) Integrated direct and indirect flood risk modeling: development and sensitivity analysis. Risk Anal 35(5):882-900

Koks EE, Jongman B, Husby TG, Botzen WJ (2015) Combining hazard, exposure and social vulnerability to provide lessons for flood risk management. Environ Sci Policy 47:42-52

Koks EE, Carrera L, Jonkeren O, Aerts JC, Husby TG, Thissen M, Standardi G, Mysiak J (2016) Regional disaster impact analysis: comparing input-output and computable general equilibrium models. Nat Hazards Earth Syst Sci 16(8):1911-1924. doi:10.5194/nhess-16-1911-2016

Kousky C, Walls M (2014) Floodplain conservation as a flood mitigation strategy: examining costs and benefits. Ecol Econ 104:119-128. doi:10.1016/j.ecolecon.2014.05.001

Mandel A (2012) Agent-based dynamics in the general equilibrium model. Complex Econ 1(1):105-121

Marchiori L, Maystadt JF, Schumacher I (2012) The impact of weather anomalies on migration in subSaharan Africa. J Environ Econ Manag 63(3):355-374

Martin IW, Pindyck RS (2014) Averting catastrophes: the strange economics of Scylla and Charybdis. NBER working paper 20215, National Bureau of Economic Research, Cambridge

McLeman R (2013) Developments in modelling of climate change-related migration. Clim Change 117(3):599-611. doi:10.1007/s10584-012-0578-2

Mechler R, Bouwer LM, Linnerooth-Bayer J, Hochrainer-Stigler S, Aerts JC, Surminski S, Williges K (2014) Managing unnatural disaster risk from climate extremes. Nat Clim Change 4(4):235-237

Miyazawa K (1976) Input-output analysis and the structure of income distribution. Springer, Heidelberg

Moussaïd M (2013) Opinion formation and the collective dynamics of risk perception. PLOS ONE 8(12)

Naqvi AA, Rehm M (2014) A multi-agent model of a low income economy: simulating the distributional effects of natural disasters. J Econ Interact Coord 9(2):1-35 
Obokata R, Veronis L, McLeman R (2014) Empirical research on international environmental migration: a systematic review. Popul Environ 36(1):1-25. doi:10.1007/s11111-014-0210-7

O'Connell E, O'Donnell G (2013) Towards modelling flood protection investment as a coupled human and natural system. Hydrol Earth Syst Sci Dis 10(6):8279-8323

Okuyama Y (2004) Modeling spatial economic impacts of an earthquake: input-output approaches. Disaster Prevent Manag 13(4):297-306

Okuyama Y, Santos JR (2014) Disaster impact and input-output analysis. Econ Syst Res 26(1):1-12

Oliva G, Panzieri S, Setola R (2010) Agent-based input-output interdependency model. Int J Crit Infrastruct Prot 3(2):76-82

Oosterhaven J, Bouwmeester MC (2016) A new approach to modeling the impact of disruptive events. J Reg Sci 56:583-595. doi:10.1111/jors.12262

Palmer PI, Smith MJ (2014) Earth systems: model human adaptation to climate change. Nature 365-366. doi:10.1038/512365a

Park J, Cho J, Gordon P, Moore JE, Richardson HW, Yoon S (2011) Adding a freight network to a national interstate input-output model: a transniemo application for california. J Transp Geogr 19(6):1410-1422

Partridge MD (2010) The duelling models: NEG vs amenity migration in explaining US engines of growth. Pap Reg Sci 89(3):513-536. doi:10.1111/j.1435-5957.2010.00315.x

Piguet E (2010) Linking climate change, environmental degradation, and migration: a methodological overview. Wiley Interdiscip Rev Clim Change 1(4). doi:10.1002/wcc.54

Pratt S, Blake A, Swann P (2013) Dynamic general equilibrium model with uncertainty: uncertainty regarding the future path of the economy. Econ Model 32:429-439

Putra HC, Zhang H, Andrews C (2015) Modeling real estate market responses to climate change in the coastal zone. JASSS 18(2):18

Quattrociocchi W, Caldarelli G, Scala A (2014) Opinion dynamics on interacting networks: media competition and social influence. Nat Sci Rep 4(4938)

Rose A (2004) Economic principles, issues and research priorities in hazard loss estimation. In: Okuyama Y, Chang S (eds) Modeling the spatial economic impacts of natural hazards. Springer, Netherlands, pp 119-142

Rose A, Guha GS (2004) Computable general equilibrium modeling of electric utility lifeline losses from earthquakes. In: Okuyama Y, Chang S (eds) Modeling the spatial economic impacts of natural hazards. Springer, Berlin, pp 119-142

Rose A, Liao SY (2005) Modeling regional economic resilience to disasters: a computable general equilibrium analysis of water service disruptions. J Reg Sci 45(1):75-112. doi:10.1111/j.0022-4146.2005. 00365.x

Rose AZ, Oladosu G (2008) Regional economic impacts of natural and man-made hazards: disrupting utility lifeline services to households. In: Richardson H, Gordon P, Moore J (eds) Economic impacts of Hurricane Katrina. Edward Elgar, Cheltenham

Rounsevell M, Arneth A, Alexander P, Brown D, de Noblet-Ducoudré N, Ellis E, Finnigan J, Galvin K, Grigg N, Harman I et al (2014) Towards decision-based global land use models for improved understanding of the earth system. Earth Syst Dyn 5(1):117

Safarzynska K, Brouwer R, Hofkes M (2013) Evolutionary modelling of the macro-economic impacts of catastrophic flood events. Ecol Econ 88:108-118

Sastry ML (1992) Estimating the economic impacts of elderly migration: an input-output analysis. Growth Change 23(1):54-79

Schelling TC (1969) Models of segregation. Am Econ Rev 59(2):488-493

Schelling TC (1978) Micromotives and macrobehavior. Norton, New York

Scrieciu S, Barker T, Ackerman F (2013) Pushing the boundaries of climate economics: critical issues to consider in climate policy analysis. Ecol Econ 85:155-165

Smith CD (2014) Modelling migration futures: development and testing of the rainfalls agent-based migration model-Tanzania. Clim Dev 6(1):77-91. doi:10.1080/17565529.2013.872593

Smith V, Carbone JC, Pope JC, Hallstrom D, Darden M (2006) Adjusting to natural disasters. J Risk Uncertain 33(1):37-54

Sobiech C (2013) Theoretical research framework. Agent-based simulation of vulnerability dynamics. a case study of the German North Sea Coast, Springer Theses, Springer, Berlin, pp 31-73

Steenge AE, Bočkarjova M (2007) Thinking about imbalances in post-catastrophe economies: an inputoutput based proposition. Econ Syst Res 19(2):205-223

Sznajd-Weron K, Sznajd J (2000) Opinion evolution in closed community. Int J Mod Phys C 11(06):1157-1165. doi:10.1142/S0129183100000936 
Tesfatsion L, Judd KL (2006) Handbook of computational economics: agent-based computational economics, vol 2. Elsevier, Amsterdam

Tobin GA (1995) The levee love affair: a stormy relationship? J Am Water Resour Assoc 31(3):359-367. doi:10.1111/j.1752-1688.1995.tb04025.x

Todo Y, Nakajima K, Matous P (2015) How do supply chain networks affect the resilience of firms to natural disasters? evidence from the great east Japan earthquake. J Reg Sci 55(2):209-229. doi:10. 1111 jors. 12119

Tsuchiya S, Tatano H, Okada N (2007) Economic loss assessment due to railroad and highway disruptions. Econ Syst Res 19(2):147-162

Tversky A, Kahneman D (1973) Availability: a heuristic for judging frequency and probability. Cogn Psychol 5(2):207-232

Tversky A, Kahneman D (1992) Advances in prospect theory: cumulative representation of uncertainty. J Risk Uncertain 5(4):297-323

van der Leeuw SE (2008) Climate and society: lessons from the past 10,000 years. AMBIO 37(14):476-482

Vigdor J (2008) The economic aftermath of Hurricane Katrina. J Econ Perspect 22(4):135-154. doi:10.1257/ jep.22.4.135

Warner K (2010) Global environmental change and migration: governance challenges. Glob Environ Change 20(3):402-413

Weisbuch G, Deffuant G, Amblard F, Nadal JP (2002) Meet, discuss, and segregate!. Complexity 7(3):55-63. doi:10.1002/cplx.10031

Wiedmann T, Minx J, Barrett J, Wackernagel M (2006) Allocating ecological footprints to final consumption categories with input-output analysis. Ecol Econ 56(1):28-48

Zhao X, Chen B, Yang Z (2009) National water footprint in an input-output framework-a case study of china 2002. Ecol Model 220(2):245-253 